LETTERS TO THE EDITOR.

IThe Editor does not hold himself responsible for opinions expressed by his correspondents. Neither can he undertake to return, or to correspond with the writers of, rejected manuscripts intended for this or any other part of NATURE. No notice is taken of anonymous communications.]

\section{Globular Clusters, Cepheid Variables, and Radiation.} Dr. Shapley makes the suggestion (NATURE, March 13) that known supplies of energy become adequate to maintain stellar and solar radiation through astronomical time if we can suppose that radiation is propagated only from matter to. matter, and is not radiated equally in all directions. In brief, we see the sun because the sun has in some way first seen us. Prof. Soddy points out (Nature, March 20) that we have no direct evidence of loss of radiation into space; "experiment and observation justify only the conclusion that radiation is propagated between portions of space occupied by, matter, .. elsewhere it may not be propagated at all." Prof. Soddy is, perhaps, on safe ground as regards laboratory experiments, but it seems to me that astronomical evidence is against him.

We see star clusters by light which has journeyed for 200,000 years to meet us; by what mechanism could this light calculate 200,00o years ago that today we should be where we are? There seem to be only two possibilities open: the cones of light projected from matter to matter may be more than big enough to catch the matter aimed at, or light may not travel in straight lines, adjusting its course as it proceeds on its voyage through space.

Under the first possibility the whole advantage of Dr Shapley's hypothesis disappears. We see, say, Io stars, so that presumably, $10^{\circ}$ stars see our sun. Suppose our sun sends out $10^{\circ}$ cones of light each big enough to be fairly sure of catching a star. Stellar velocities being of the order of $\mathrm{IO}^{-4}$ times that of light, each cone must be of angle about $\mathrm{IO}^{-4}$. radians, and $10^{9}$ such cones just about fill up the solid angle of space. The hypothesis hás lost its only advantage.

Suppose, as an alternative, that the presence of a star in some way guides the light from another: star towards it. The path of a ray of light is no longer a straight line, but a sort of "curve of pursuit." To catch the light from a star we ought no longer to point our telescopes $20^{\prime \prime} \times \sin \lambda$ forward along the earth's path in space, but an equal amount backwards. The aberration-correction becomes reversed, and all determinations of parallax: proper motions, etc., become illusory. One puzzle might be solved, but at the cost of shattering almost the whole fabric of astronomy.

Thus if Dr. Shapley's very strong case for a long time-scale is accepted as proved, I think we must look for a new mechanism of production of energy; the problem is not solved by a mere rearrangement of the expenditure. In looking for possible new sources of energy, we ought to remember that our knowledge of phvsics is derived wholly from experiments conducted at the surface of a planet with the aid of light emitted from the surfaces of sun and stars. Our whole knowledge of physics is "surface-physics"; it is the special physics of conditions in which radiation is free to scatter into space, so that radiation pressure is negligible. There may be a more general physics applicable inside a star, and this mav contain sources of energy unknown to us. There is, for instance, a possibility I suggested in 1905. which Dr. Shaplev considers "bizarre." Conservation of mass and of energy may be only phenomena of "surface-phvsics." Inside a star, matter and energy may be interchangeable The intrinsic energy of an electron being $m \mathrm{C}^{2}$, the transformation of $i$ ner cent. of the sun's mass into energy would yield up radiation enough for I50.000.000,000 vears.

J. $\mathrm{H}$ JEANS.

March 22.

NO. 2578 , VOL. IO3]
THE suggestion of Dr. Harlow Shapley and Prof. Soddy that radiation only occurs between portions of space occupied by matter is difficult to reconcile with the very considerable cooling by radiation that takes place on a cloudless night, when, on the supposition in question, it should be almost negligible-less, indeed, than with an overcast sky.

Such a law of radiation would have other strange results equally inconsistent with experience.

JoHN W. Evans.

Imperial College of Science and Technology, South Kensington, March 21.

Scientific Research at St. Andrews University.

THE president of the Edinburgh Royal Society in his address alluded to in NATURE of March $1_{3}$ has done full justice to the St. Andrews University Chemical Research Department, which owes its prosperity to the munificence and the example of my late colleague, Prof. Purdie, and also to his relatives. It likewise throughout has had the unvarying support of the University Court, which allocated a large sum (more than 5oool.) from the Carnegie Trust Grant to the University for its maintenance.

But there is an older research department in the University of St. Andrews which has been overlooked by Dr. Horne, viz. that for research in marine zoology and the fisheries at the Gatty Marine Laboratory, the oldest marine laboratory in Britain, and the scientific work emanating from which will speak for itself. Its trained workers hold, and have held, important posts in the three centres of the kingdom and in the various Colonies, as well as in foreign countries. That it should have been severed from connection with the Government by the Secretary for Scotland in 1896 (after twelve and a half years' labour), when the new building was erected on University ground, seems a paradox when the heavy expenditure (which still goes on) in subsidising the International Fisheries Council is remembered.

Chemistry research, adequately endowed, can be carried out anywhere, whereas work in marine zoology and the fisheries can nowhere be more successfully pursued than in the bay and on the shores of St Andrews, where Prof. John Reid, the distinguished physiologist, first dealt with its riches. There the pulse of the North Sea is daily felt, and every student of Nature is beckoned to engage in the elucidation of the endless variety of its fauna and flora. It is to be hoped that the University Court, which has closed the laboratory at present from motives of economy, will soon reopen it.

W. C. McIntosh.

\section{Maceration by Tryptic Digestion.}

WITH reference to the paragraph on the method of maceration by tryptic digestion in NATURE of March 6 , p. 9, it may be of interest to your readers to learn that further work on the process has shown that equally good results are obtained by the use of Messrs. Allen and Hanbury's Liquor Trypsini Co. This costs only $3 s$. $9 d$. a bottle, and the requisite strength is obtained by adding $I$ c.c. to a litre of water. The procedure is in other respects identical with that previously described. The trouble of dissolving the powder is thus avoided, and the cost is reduced from Is. per litre to rather less than $\frac{1}{2} d$., so that the method becomes practicable for use on a large scale.

On the whole, the optimum temperature is a high one, about $55^{\circ} \mathrm{C}$., and this has the additional advantage of somewhat reducing the unpleasant smell.

KathILEN F. LANDER.

Zoological Society of London, Regent's Park, N.W.8, March ig. 